\title{
O OLHAR EPISTEMOLÓGICO COMPLEXO, TRANSDISCIPLINAR E ECOFORMADOR NO CONTEXTO SOCIOAMBIENTAL CONTEMPORÂNEO
}

\author{
Kênia Paulino de Queiroz Souza \\ Universidade Federal de Tocantins - UFT (Brasil) \\ keniaqueiroz06@hotmail.com·https://orcid.org/0000-0002-7352-824X \\ Marina Haizenreder Ertzogue \\ Universidade Federal de Tocantins - UFT (Brasil) \\ marina@mail.uft.edu.br· https://orcid.org/0000-0002-7888-9888 \\ Marlene Zwierewicz \\ Universidade Alto Vale do Rio do Peixe - UNIARP (Brasil) \\ Marlenezwie@yahoo.com.br· http://orcid.org/0000-0002-5840-1136
}

\begin{abstract}
Resumo. A epistemologia complexa tem se mobilizado em meio à crise socioambiental que afeta diferentes instâncias da realidade local e global, sendo motivada pela necessidade de estimular a capacidade de enfrentamento das adversidades que se consolidam no contínuo processo formativo. Nesse sentido, este artigo tem por objetivo refletir à luz da epistemologia complexa e ecoformadora sobre a interligação entre o ser humano, a sociedade e o meio ambiente a partir do contexto educacional. Para tanto, optou-se metodologicamente pela revisão bibliográfica a partir de uma abordagem qualitativa apoiada em pensadores como: Mallart (2009), Moraes (2008; 2014), Morin (2009; 2015), Nicolescu (1999), Silva (2008), Zwierewicz (2011) e Wulf (2016). Este estudo propiciou a compreensão de que é urgente repensar o contexto formador diante das questões que se tem vivenciado no âmbito individual, social e ambiental, pois cada vez mais de forma instável, conflituosa e desafiadora o ser humano enfrenta um cenário que incentiva a reprodução e a simplificação de discussões educacionais que visam à interligação da vida planetária. Esse repensar parte do enfrentamento ao olhar reducionista e fragmentado que há muito tem sido utilizado. É nesse contexto que a epistemologia complexa e a ecoformação assumem uma posição de relevância na formação, especialmente quando possibilidades habituais não são suficientes para solucionar os problemas que afetam a realidade socioambiental.
\end{abstract}

Palavras-chave: Complexidade, Transdisciplinaridade, Ecoformação.

\section{THE COMPLEX, TRANSDISCIPLINARY AND ECOFORM EPISTEMOLOGICAL LOOK UNDER THE CONTEMPORARY SOCIOENVIRONMENTAL CONTEXT}

\begin{abstract}
. the complex epistemology has been mobilized in the midst of the social and environmental crisis that affects different instances of local and global reality, being motivated by the need to stimulate the ability to face the adversities that are consolidated in the continuous formative process. In this sense, this article aims to reflect in the light of the complex and ecoform epistemology about the interconnection between the human being, society and the environment from the educational context. To this end, a methodological choice was made for the literature review from a qualitative approach supported by thinkers such as: Mallart (2009), Moraes (2008; 2014), Morin (2009; 2015), Nicolescu (1999), Silva (2008), Zwierewicz (2011) and Wulf (2016). This study provided the understanding that it is urgent to rethink the formative context in the face of the issues that have been experienced in the individual, social and environmental, because increasingly unstable, conflicting and challenging human beings face a scenario that encourages reproduction and the simplification of educational discussions aimed at the interconnection of planetary life. This rethinking part of the confrontation to the reductionist and fragmented look that has
\end{abstract}


long been used. It is in this context that complex epistemology and ecoforming assume a position of relevance in formation, especially when habitual possibilities are not sufficient to solve the problems that affect socio-environmental reality.

Keywords: Complexity, Transdisciplinarity, Ecoforming.

\title{
LA MIRADA EPISTEMOLÓGICA COMPLEJA, TRANSDISCIPLINARIA Y ECOFORMADORA EN EL CONTEXTO SOCIOAMBIENTAL CONTEMPORÁNEO
}

\begin{abstract}
Resumen. La epistemología compleja se ha movilizado en medio de la crisis social y ambiental que afecta a diferentes instancias de la realidad local y global, motivada por la necesidad de estimular la capacidad de enfrentar las adversidades que se consolidan en el proceso formativo continuo. En este sentido, este artículo tiene como objetivo reflexionar a la luz de la epistemología compleja y ecoformadora sobre la interconexión entre el ser humano, la sociedad y el medio ambiente desde el contexto educativo. Con este fin, se realizó una elección metodológica para la revisión de la literatura desde un enfoque cualitativo apoyado por pensadores como: Mallart (2009), Moraes (2008; 2014), Morin (2009; 2015), Nicolescu (1999), Silva (2008), Zwierewicz (2011) y Wulf (2016). Este estudio propició la compreensión de que es urgente repensar el contexto de formación por lo que se vivencia individual, social y ambientalmente, ya que de forma cada vez más inestable, conflictuosa y desafiante el ser humano enfrenta un escenario que estimula la reproducción y la simplificación de las discusiones educativas dirigidas a la interconexión de la vida planetaria. Este replanteamiento debe servir de confrontación con la mirada reduccionista y fragmentada que se há utilizado durante mucho tiempo. Es en este contexto que la epistemología compleja y la ecoformación asumen una posición de relevancia en la formación, especialmente cuando las posibilidades habituales no son suficientes para solucionar los problemas que afectan la realidad socioambiental.
\end{abstract}

Palabras clave: Complejidad, Transdisciplinariedad, Ecoformación.

\section{Introdução}

A educação do século XXI tem enfrentado muitas adversidades que afetam as diferentes etapas de ensino. As "universidades em particular, precisam lidar cumulativamente com os problemas velhos e novos e os desafios cada vez mais complexos" (Neves, 2007, p. 15).

Em decorrência disso, ampliam-se as dificuldades para que as Instituições de Ensino Superior priorizem ações socioambientais e exerçam sua função social, humanística e planetária, para que seus objetivos estejam conectados com um bem comum e promovam o bem-estar individual, social e ambiental.

Isso converge com proposições que permeiam outros contextos em busca de mudanças na sociedade. Assim, emergem concepções de formação para vida, a epistemologia complexa e a ecoformação, ou seja, perspectivas que possibilitam a formação de pessoas autônomas, estimuladas a produzir, socializar e interligar contextos e conhecimentos diversos, buscando superar o olhar fragmentado que separa o ser humano da sociedade e do meio ambiente.

A ecoformação é "uma educação ao longo da vida e em todos os setores da prática humana, mediada pela relação do homem consigo mesmo, com os outros e com o ambiente" (Silva, 2008, p. 100). Ela "se alimenta do paradigma ecológico, interrogandose sobre as relações entre o ser humano e o mundo" (Gadotti, 2001, p. 91). 
Nessa relação, a ecoformação e a epistemologia complexa se encontram aliadas a uma educação transformadora, em uma integração que busca a interligação do ser humano com o outro, com o ambiente e consigo mesmo. Segundo Dittrich, Espindola e Koefender (2013), uma educação ecoformadora procura cuidar do ser humano de forma que ele mesmo seja autor de sua existência, coautor de seu entorno e da preservação do seu planeta.

Para tanto, é preciso repensar a forma de perceber a vida integralmente, o que requer um pensar complexo e ecoformador, que vai além do olhar local e separado. É necessário, portanto, um olhar ampliado, é preciso ver o global e suas teias de conexão entre o ser, o social e o ambiental e, sobretudo, valorizar o compromisso como um bem comum (Zwierewicz, 2011).

Também se mostra imprescindível compreender que essa visão epistemológica prima por uma formação emancipatória. Isso quer dizer atuar de modo comprometido com criações voltadas às diferentes situações e circunstâncias do meio, que envolvem o ser humano tanto em seu exterior quanto no interior, despertando-o para ações que se transformem em bens socioambientais.

Nesse sentido, sedimentam-se no contexto brasileiro discussões complexas e ecoformadoras, cujos conceitos, valores e fundamentos agregam às vivências educacionais um olhar global, interligado ao humano, à sociedade e ao planeta, fazendo emergir novas possibilidades de vida a partir do contexto educacional.

\section{Procedimentos metodológicos}

Este artigo é um recorte de parte da discussão teórica que fundamenta a pesquisa de doutoramento da primeira autora sobre problemáticas socioambientais. Assim sendo, a pesquisa parte da seguinte reflexão: a epistemologia complexa tem contribuído para analisar as consequências de um paradigma educacional tradicional que pode favorecer o distanciamento da humanidade das reais necessidades do planeta, estimulando atitudes individualistas que geram consequências para o coletivo (vidas socioambientais) (Mallart, 2009).

Entre esses problemas estão a contaminação e a degradação dos ecossistemas, o esgotamento do bem comum, o crescente aumento da destruição da biodiversidade, a perda da diversidade biológica, linguística e cultural, "Tudo isso acrescentado a uma profunda crise econômica global que não parece ser uma crise de crescimento, mas sim uma mudança de sistema" (Mallart, 2009, p. 29).

Diante dessa problemática, esta discussão tangencia-se pelo seguinte questionamento: como as bases epistemológicas da complexidade e da ecoformação norteiam a conexão entre o ser humano, a sociedade e o meio ambiente, numa dimensão planetária? Para responder, objetivamos refletir, à luz dessas bases epistemológicas, sobre a interligação entre o ser humano, a sociedade e o meio socioambiental a partir do contexto educacional.

Em relação ao tipo de pesquisa deste recorte, é explorada a revisão bibliográfica com abordagem qualitativa apoiada nos seguintes pensadores: Mallart (2009), Moraes (2008; 2014), Morin (2009; 2015), Nicolescu (1999), Silva (2008), Zwierewicz (2011) e Wulf (2016), os quais discutem sobre complexidade, transdisciplinaridade, ecoformação e a interligação entre o ser humano e a natureza. 
Para Gil (2002, p. 44), “a pesquisa bibliográfica é desenvolvida com base em material já elaborado, constituído principalmente de livros e artigos científicos". Nesse sentido, a escolha da pesquisa bibliográfica foi guiada pelo objetivo e pelos fundamentos epistemológicos a que se propôs.

Minayo (2001) lembra que a pesquisa com abordagem qualitativa tem um compromisso social com a comunidade que faz parte da investigação, uma vez que, eticamente, aprofunda-se no universo das definições de suas ações e relações e se compromete a propiciar uma devolutiva.

\section{Resultados e discussões}

A educação contemporânea é permeada por suas raízes históricas, que podem complementar a construção de novos saberes com ações formativas mais fundamentadas, conectadas e fortalecidas. As ações de hoje, no contexto educacional, não são criações exclusivas de inspirações atuais, mas, sim, experiências do passado interligadas com vivências do presente, ocasionando diversas mudanças na realidade complexa.

Cunha (2005) reforça essa vinculação temporal ao defender que o hoje é construído com a valorização do passado, sendo que o ser humano reconhece sua historicidade e a considera na reconstrução contemporânea. Nesse processo, o ser humano não se dissocia do meio ambiente, pois faz parte de um contexto único sem perder sua especificidade.

Torre (2009) identifica mudanças na maneira de viver da humanidade organizando-as em quatro etapas ou ondas, que são vinculadas ao período agrícola, ao processo de industrialização, ao desenvolvimento da criação das telecomunicações e à onda quântica ${ }^{i}$ Segundo o autor, essa última é a que se vivencia neste século, e suas características superam óticas positivistas, fragmentadas e subdivididas, constituindo-se como uma visão ampliada, que busca perceber o todo.

Portanto, "a física quântica, a nova biologia, a neurociência e a neuroplasticidade, o conhecimento transpessoal estão abrindo o caminho a um novo paradigma e a uma nova onda conceitual (ontológica e epistemológica) da realidade" (Torre, 2009, p. 18).

Ontológica porque valoriza o ser interior do sujeito, o qual está imbricado em uma multidimensionalidade intrínseca que interliga suas ações com o exterior. Nessa acepção complexa, aproxima-se com a percepção de Pinto (2011, p. 52) de que "a ontologia se refere à natureza dos fenômenos físico, biológico e social. Trata-se das questões relacionadas à realidade e ao ser multidimensional".

Também é epistemológica porque busca o conhecer, no qual se adentra, sem fronteiras reducionistas, no mundo das descobertas, abrindo-se a novos saberes. Parte "do entendimento de como se conhece; ... trata especificamente do método de abordar o conhecimento" (Pinto, 2011, p. 56).

Abrir-se a novos conhecimentos é perceber que o mundo é composto por problemáticas sem as quais não haveria possibilidades de novas reconfigurações. $\mathrm{O}$ mundo não é linear e não atende somente a um dos extremos resultados de uma visão dicotômica que separa as percepções humanas em parte-todo, simples-complexo, localglobal, unidade-diversidade, particular-universal etc. Uma condição não existe sem a outra, ambas se complementam, mesmo sendo antagônicas. 
Santos, Sanchez, Santos e Bueno (2014) justificam a necessidade de ampliar a percepção atual ao afirmar que, na perspectiva da modernidade, a educação tem como princípio a especialização a partir da disciplinarização fundamentada no método científico como verdade universal, objetiva e racional.

Contudo, observa-se que, no século XXI, convivem diferentes concepções de ensino em um mesmo cenário, sendo que algumas das Instituições de Ensino Superior dinamizam práticas norteadas tanto pela perspectiva da epistemologia complexa como pela concepção conservadora. Enquanto a primeira promove a aproximação do sujeito com o objeto de estudo, a segunda trabalha com uma perspectiva de ensino tradicional, subdivido, que descontextualiza, classifica, reduz e separa os saberes.

Para compreender as bases que permeiam a superação dessa perspectiva de ensino tradicional pelo viés da epistemologia complexa, recorre-se a autores como Morin (2001). Este autor afirma que a ideia de complexidade tem sua origem mais vinculada ao cotidiano do senso comum do que propriamente à ciência. Sem uma identidade definida, a complexidade já perpassava alguns terrenos das áreas do conhecimento. De forma indireta, ela surgiu no âmbito da ciência na microfísica e na macrofísica, embora ainda não fosse reconhecida como tal no século XX.

A microfísica ainda não a percebia em sua totalidade, apenas atentava para a complexidade da relação entre observador e observado, mas não conseguia ir além, ver que todos os fenômenos naturais também eram tratados, inclusive do corpo e do cérebro humano. Já a macrofísica compreendia que os resultados da observação eram determinados a partir do local em que se encontrava o observador. Todavia, Morin (2001) alerta que, naquele período moderno, essas complexidades não eram aceitas, predominando a ótica da simplificação, do reducionismo.

Morin (2001, p. 51) afirma que, por volta da década de 1960, com os estudos dos instituidores da cibernética, Wiener e Ashby, "a complexidade entra verdadeiramente em cena na ciência. É com Von Neumann que, pela primeira vez, o caráter fundamental do conceito de complexidade aparece na sua ligação com os fenômenos de autoorganização".

Assim, foram necessários os avanços das tecnologias informatizadas para se perceber a relevância da complexidade não só na educação, como também na compreensão de diversos contextos da vida.

A princípio, então, o reconhecimento da complexidade partiu de sua ligação com a cibernética. No início, esta compreendia a complexidade como um fenômeno quantitativo, diante do número de inter-relações. Entretanto, com o aprofundamento das discussões, passou-se a compreendê-la também de modo subjetivo, além do objetivo nas incertezas, instabilidades, incorreções, indeterminações -, interligado aos fenômenos diversos e aleatórios, com um mesclado de ordem e desordem que não se posiciona em relação a dualidades de campos opostos, mas, sim, de forma conectada.

A complexidade não é uma confusão, mas uma interligação no campo da autoorganização, sendo uma dialogicidade tríade entre a ordem, a desordem e a organização, ou seja, um olhar que propicia reconhecer a existência de um mundo complexo (Morin, 2001). É relevante compreender a complexidade a partir da perspectiva interligadora, que Morin apresenta do seguinte modo:

Complexus significa o que foi tecido junto; de fato, há complexidade quando elementos diferentes são inseparáveis constitutivos do todo (como o econômico, o político, o sociológico, o psicológico, o afetivo, o mitológico), 
e há um tecido interdependente, interativo e inter-retroativo entre o objeto de conhecimento e seu contexto, as partes e o todo, o todo e as partes, as partes entre si. (Morin, 2000, p. 38).

Essa tessitura é a união entre a complexidade e a simplicidade. A complexidade, nessa visão, refere-se à interligação do todo, compreendendo que nada é separado de tudo, dessa forma a vida não subsiste nem mesmo nasce. Existe uma interligação com o outro, com a sociedade e com o meio ambiente.

Morin (2001, p. 149) vai além sobre o contexto teórico complexo e afirma que "a complexidade não é apenas a união da complexidade e da não-complexidade (a simplificação); a complexidade encontra-se justamente no âmago da relação entre o simples e o complexo porque uma tal relação é ao mesmo tempo antagônica e complementar".

Com esse entendimento referente à complexidade, antes mesmo de ela ser percebida como um conceito, o ser humano despertou para as interligações necessárias na dimensão planetária. Humboldt, por exemplo, geógrafo europeu do século XIX, foi um dos primeiros a perceber essa interligação. Para ele, a natureza ${ }^{i i}$ não estava isolada de tudo, mas havia uma teia de conexão, uma unidade, o todo.

A natureza, Humboldt atinou, era uma teia de vida e força globais. Mais tarde, um colega afirmou que Humboldt foi o primeiro a compreender que tudo estava entretecido como que por "mil fios". Essa nova ideia de natureza mudaria a maneira como as pessoas entenderiam o mundo. (Wulf, 2016, p. 135-136).

Essa percepção de Humboldt ocorreu pelas conexões que ele conseguiu fazer com toda uma vida de estudos em diferentes contextos. Para Humboldt (1950), tudo era interação e ao mesmo tempo reciprocidade, o autor chegou até mesmo a perceber um princípio da causalidade, ou seja, onde havia uma causa, viria uma consequência. Nesse sentido, sobre a visão de Humboldt, Marcolini (2009, p. 1) explicita que "todos os fenômenos naturais obedeciam a uma física do mundo, que regia e interligava a terra, o mar e a atmosfera às plantas, animais e sociedades".

Com essa visão para a natureza, Humboldt começou a perceber a sua degradação como consequência da ação humana. O seu olhar ampliado, além da botânica, via as interligações entre o humano e a natureza. Essa nova ótica que começou a permear a vida de Humboldt vai ao encontro da perspectiva da epistemologia complexa, no sentido de o autor perceber que as certezas que outrora o guiavam pelas suas viagens se tornaram incertezas diante das transformações ocorridas no contexto socioambiental que ele seguia analisando.

Para Morin (2009, p. 63), "o conhecimento é, com efeito, uma viagem que se efetiva num oceano de incerteza salpicado de arquipélagos de certeza". Refletir sobre a dimensão do oceano nesse contexto de discussão que a complexidade revela como o universo do saber ainda é ação extensa e que se abre para outros novos conhecimentos.

Diante dessa valorização da unicidade, os diferentes lados, vistos como opostos na concepção moderna, passam a se tornar complementares, conectados com a nova visão da complexidade em relação à ação educativa. Sobre isso, Morin (2009) reafirma que é essencial uma reforma de pensamento, para religar o que se encontra subdividido. Nesse sentido, o contexto do Ensino Superior deve proporcionar mudanças de dentro para fora: antes de práticas pedagógicas diferenciadas, precisa-se de pensamentos interligadores, de pessoas que acreditem nessa visão. 


\section{- Princípios de conexão}

A partir da mudança no pensar, cuidando-se do interior, será possível entender a si mesmo, conhecer diferentes perspectivas teóricas e, consequentemente, propor interferências necessárias para a mudança no campo educacional numa dimensão socioambiental.

Diante disso, Morin (2009) apresenta três princípios de religação ecológica dos saberes: o recursivo, o dialógico e o hologramático, que são operadores cognitivos do pensamento complexo e funcionam como vias para entender e viver a interconexão planetária.

A compreensão da realidade educativa a partir do princípio recursivo propicia o entendimento de que o ser humano, no contexto do Ensino Superior, tanto sofre mudanças quanto faz alterações, pois, ao mesmo tempo que interfere no processo educativo, também recebe interferências na sua concepção e na ação de intervir. Por isso, Morin (2009) afirma ser esse um princípio que pode ser ilustrado em forma de espiral, em que se passa por caminhos abertos, curvas, altos e baixos que compõem o avançar da caminhada e, ao mesmo tempo que se prossegue, novos percursos vão sendo construídos.

Para Moraes (2008, p. 100), esse princípio "possui natureza autopoiética, ou seja, autoprodutora daquilo que a produz". Opostos se integram, e sujeito e objeto se unem sem se tornar homogêneos. Segundo Morin (2009, p. 66), "uma sociedade é o produto das interações entre os indivíduos que a compõe", ou seja, ao passo que constrói, autorreconstrói-se - operando uma interligação entre o saber, o ser e o fazer.

O segundo princípio para a religação é a dialógica, que Morin (2009) explicita como necessária para o enfrentamento de realidades densas e contrárias que não são percebidas como um erro. Para Moraes (2008), esse é considerado como um dos mais importantes princípios, pois desperta para a consciência da importância de os antagônicos tornarem-se complementares.

O princípio dialógico não parte de si mesmo, ou do nada, ele caminha a partir do princípio recursivo, tendo, como sua representação, a imagem espiral. Isso porque nessa imagem não há uma visão de início e fim, mas de dialogicidade e equilíbrio entre processos diferentes.

Moraes (2008, p. 102) assinala que "é a natureza dialógica da complexidade que nos leva a compreender as relações equilíbrio/movimento, rigor/espontaneidade, mudança/permanência, objetividade/subjetividade como bases estruturais para a vida". É uma natureza que harmoniza processos diferentes, sem perder a sua essencialidade, mas habitando terrenos comuns; não são inimigos, mas, sim, complementam-se, propiciando novos entendimentos sobre a vida, bem como diferentes olhares em relação ao fenômeno envolvido.

A tríade dos princípios para religar os saberes que corroboram a aprendizagem, a partir do pensar complexo, complementa-se com o hologramático (Morin, 2009). O autor demonstra a importância de perceber que não só as partes ou o todo são importantes, mas que não se escolhe um ou outro, pois ambos têm elementos insubstituíveis.

Morin (2009, p. 67) explica que "a sociedade, entendida como um todo, também se encontra presente em nosso próprio interior, porque somos portadores de sua 
linguagem e sua cultura". Trata-se de um princípio que valoriza o outro, a dialogicidade entre um objeto, um sujeito e/ou uma organização tanto no micro como no macrocampo, buscando-se perceber a complexidade existente. Santos (2009, p. 19) afirma que "assim, o princípio hologramático remete à articulação dos pares binários: parte-todo, simplescomplexo, local-global, unidade-diversidade, particular-universal". Assim, compreendese que o todo e as partes dialogam para serem reconhecidos pelo outro e se autorreconhecerem.

Os três princípios para religar os saberes: o recursivo, a dialógica e o hologramático se entrelaçam como operadores que colaboram para compreender a realidade multidimensional e multirreferencial percebida a partir do cenário educacional. A complexidade desse cenário é ainda maior do ponto de vista complexo e transdisciplinar, pois se refere às pessoas envolvidas e ultrapassa os muros de uma instituição que propicia influências.

Nesse aspecto, há também a multidimensionalidade interior de cada ser humano e a pluralidade de referências, ideias, concepções, imprevisibilidades, dentre outros aspectos - sociais, econômicos, políticos, religiosos, culturais, cognitivos, emocionais que a mutabilidade do tempo propicia velozmente, junto com as dimensões ambientais. Entretanto, ainda estaria distante a possibilidade de relatar as interferências da realidade complexa, e muitas delas nem seriam percebidas pelos olhares humanos.

A perspectiva complexa apresenta, hoje, elementos possíveis para perceber e compreender a realidade macro e micro em relação ao contexto do Ensino Superior e, ainda, a possibilidade de ser menos mutiladora do saber. Além de, também, propiciar conhecimentos que se integram nas dimensões ontológica (ser), epistemológica (conhecer) e metodológica (fazer) para a sistematização da ação educativa, tanto no contexto educacional quanto em outros cenários. Entretanto, para compreender esse caminho, Ribeiro e Moraes (2014, p. 87) afirmam que se exige

a capacidade de reconhecer que para se admitir tal possibilidade será necessário: superar o paradigma da simplificação como primeira exigência; correr o risco de lançarse na incerteza, na improbabilidade, admitindo que se esteja no campo da ciência, como segunda exigência; abrir-se à possibilidade de ampliar o campo de visão para enxergar na dimensão sistêmica a beleza da dialógica dos paradoxos que ao mesmo tempo se complementam e se religam. Essa visão consiste na terceira exigência, que nos leva a reconhecer a condição de complementaridade dos opostos como recurso para perceber o que ainda não foi visto.

Nesse sentido, a cada dia se percebem mais inferências de caos, tanto individual quanto social, cultural, econômico, político e ambiental, com forte influência do ser humano. Mas, sem se deter nesse caminho que requer grandes discussões, aqui destacamos que a vida é permeada por múltiplas dimensões, e a perspectiva educativa precisa encontrar-se interligada também com múltiplos sistemas referenciais.

Nessa multiplicidade, Moraes (2008, p. 101) afirma que "a complexidade da realidade exige também outras formas de explicação ou de interpretação da realidade e incentiva a criatividade, bem como a combinação de determinados tipos de estratégias, epistemológica e metodologicamente compatíveis", procurando a dinamicidade da não linearidade e as diversas dimensões da aprendizagem, uma vez que não se pauta em um único caminho, mas há amplitude dos olhares para o cenário educacional. 
Diante disso, percebe-se que a visão complexa busca essas tessituras sociais como um todo e em conjunto, abrangendo desde uma docência interligadora até um contexto maior, educacional e planetário, por meio do pensamento complexo.

\section{- Docência interligadora: um pensar transformador}

A docência pode ser compreendida por meio da epistemologia complexa como "um conjunto de atitudes dos docentes entre as quais se pressupõe tomar consciência da importância do contexto multidimensional da educação e do ser humano, transgredir o ciclo transmissivo e reprodutivo do conhecimento" (Pinto, 2011, p. 44). Dessa forma, compreende-se esse conjunto de atitudes como inter-relações entre diversos saberes além dos científicos, reconhecendo-os com o mesmo nível de importância apresentado pela ciência. A partir desse olhar complementar no âmbito dos saberes, podem surgir novas concepções na educação.

Dentre as perspectivas que demonstram a valorização histórica das construções, e seus vários elos conectores, está a interligação entre os contextos socioambientais. Com essa conexão, pode-se ir além, ultrapassar disciplinas e demais saberes, ou seja, alcançar o viés transdisciplinar.

Para Nicolescu (1999, p. 51, grifos do autor), a transdisciplinaridade, "como o prefixo 'trans' indica, diz respeito àquilo que está ao mesmo tempo entre as disciplinas, através das diferentes disciplinas e além de qualquer disciplina." Seu objetivo é a compreensão do mundo presente, para o qual um dos imperativos é a unidade do conhecimento.

A transdisciplinaridade vai além dos métodos e dos conhecimentos científicos, ela busca compreender a dimensão do saber em sua amplitude e complexidade de ser, ao perceber portas nas disciplinas, ver pontes entre elas. Nesse contexto, transitar e interligar diversos saberes que fazem parte da vida no planeta nos leva a perceber que cada elemento constituinte do meio social, ambiental, humano e cultural tem sentido interconectado entre si mesmo.

Essa concepção transdisciplinar, portanto, trata de uma educação que busca construir junto, com o outro, com o meio ambiente e consigo mesmo, para perceber a vida com um olhar mais ampliado, onde tudo está conectado e interligado com o planeta. A essa perspectiva a ecoformação se integra, com o objetivo de estimular um viver conectado com a natureza, uma formação integral humana, visto que o ser humano está interligado com o outro, o ambiente, a cultura, a sociedade e consigo mesmo.

Nesse contexto, a existência planetária tem sido vista com um olhar mais humanizado e solidário, não só pelo bem do ambiente em si, mas também, e principalmente, pela dependência que os seres viventes têm da ecologia ${ }^{\text {iii }}$.

Nesse sentido, o meio ambiente, nos dias de hoje, pode ser percebido por meio da epistemologia complexa e da ecoformação, com uma percepção diferenciada de que as partes são conectadas ao todo da vida no planeta, interligadas, por sua vez, com outros seres viventes.

Entretanto, esse olhar ainda é de poucos e de ações quase inexistentes para a dimensão planetária, ou seja, que valorizam essa preservação inter-relacional entre meio ambiente e seres humanos. Há ainda muito o que discutir, com consciência, sobre isso 
para, consequentemente, intervenções serem desenvolvidas, como ações que podem começar nos cenários de Ensino Superior, facilitando a compreensão aos interessados sobre a relevância de interligar-se ao universo.

O contexto educacional na visão complexa e ecoformadora abrange todas as dimensões da vida humana e ecológica, buscando viver em harmonia, paz, equilíbrio e em conexão entre os diferentes tipos de existência no planeta, caminhando na contramão de um pensamento que tudo separa e simplifica.

A mudança desse pensamento reducionista e fragmentado para um pensamento complexo implica, portanto, em uma educação ecoformadora. Nesse sentido, para Galvani e Pineau (2012, p. 217), "formar-se em complexidade é aprender a reconhecer o concreto do princípio dialógico presente nas relações de autonomia/dependência que acontece nas interações entre o si (auto), o outro (socio) e o cosmos (eco)".

De acordo com Gadotti (2001), o termo "ecoformação" surgiu com Gaston Pineau, ao aprofundar seus estudos sobre a autoformação, na década de 1980, relacionando as histórias de vida que as pessoas expressavam sobre o meio ambiente em seu cotidiano.

A partir da formação do Grupo de Pesquisa sobre Ecoformação (GREF), criado em 1992, coordenado por Pineau, junto com o Laboratório de Ciências da Educação da Universidade François Rabelais de Tours, surgiram mais discussões sobre esse tema (Silva, 2008).

A temática é discutida por diversos teóricos, fazendo correlações com diferentes teorias. Inclusive, para Silva (2008), a perspectiva ecoformadora no contexto educacional inter-relaciona-se com a ótica de Jean-Jacques Rousseau sobre os três mestres: o homem (natureza), os outros (a sociedade) e as coisas (o ambiente). A autora correlaciona-a com a trindade humana indivíduo/espécie/sociedade na visão de Morin.

Para esse formar-se complexo, é necessário repensar as concepções de mundo e o modo como se interage nele. A humanidade contemporânea ainda não está preparada para lidar com os problemas atuais que têm afligido a dimensão planetária, muitos dos quais concebidos pela sua própria ignorância, fundamentada num pensamento simplificador. A sociedade vive em meio a sérias situações-problemas, "descarregamento ecológico, exclusão social, exploração sem limites dos recursos naturais, busca frenética e desumanizante do lucro, aumento das desigualdades encontram-se no cerne das problemáticas contemporâneas" (Morin, 2015, p. 5). Esse despreparo origina-se de uma formação linear, subdividida e reducionista, que impossibilita o ser humano de ver sua ação inter-relacionada com essas degradações do meio ambiente. Para Moraes (2014, p. 22-23), na atualidade os problemas são ainda maiores. $O$ autor caracteriza-os como emergentes, conforme elencados a seguir:

1) a globalização competitiva decorrente de uma visão unilateral de desenvolvimento;

2) um consumismo exacerbado, moldando desejos, vontades e relações humanas;

3) um desenvolvimento material inquestionável, mas do qual pouco (sic) são aqueles que verdadeiramente dele desfrutam, ao mesmo tempo que vem provocando uma degradação ecossistêmica e meio-ambiental sem precedentes na história de nossa civilização, diminuindo a qualidade de vida no planeta Terra; 
4) uma civilização ocidental insensível ao problema da fome, já que a geografia da pobreza se expande cada vez mais. De um modo geral, somos insensíveis ao subdesenvolvimento humano e nos acostumamos com o aumento da violência muito rapidamente, assim como o médico se acostuma com a morte rodando ( $\mathrm{sic}$ ), diariamente, os corredores hospitalares. Somos também insensíveis aos problemas docentes e discentes que afligem nosso contexto educacional e que vem (sic) comprometendo, seriamente, não apenas a qualidade da educação oferecida às gerações atuais, mas principalmente, o futuro e a esperança de uma imensa geração de brasileiras e brasileiros, que se sentem impotentes e vulneráveis diante de tudo o que acontece.

Essas problemáticas não fazem parte de um único país, ou de alguns, e não são situações desvinculadas da educação, são ações que inter-retroagem no contexto planetário. Entretanto, diante de tantas situações-problemas, a educação tem papel fundamental no repensar da realidade atual.

O espaço universitário, principalmente, deve ser importante propulsor de atitudes conscientes em relação à articulação de uma vida ambiental e humana mais equilibrada, buscando um viver social mais sustentável para a presente geração e para as futuras.

Além dessa ótica do todo, busca-se um caminho, com estratégias que direcionem as ações por novos horizontes, para haver diferentes reconfigurações da vida, ressignificando contextos desestruturados nas dimensões sociais e ambientais. Desse modo, a perspectiva ecoformadora propõe:

a) vínculos interativos com o meio natural e social, pessoal e transpessoal; b) desenvolvimento humano a partir e para a vida, em todas suas dimensões e manifestações de maneira sustentável. A sustentabilidade é um traço fundamental da ecoformação e de todos os conceitos relativos a "eco"; c) caráter sistêmico e relacional que nos permite entender a formação como redes relacionais e campos de aprendizagem; d) caráter flexível e integrador das aprendizagens, tanto por sua origem multissensorial e interdisciplinar como por seu poder polinizador; e) primazia de princípios e valores ambientais que tomam a Terra como um ser vivo onde convergem os elementos da natureza. (Torre et al., 2008, p. 21-22)

Essas características são princípios auto-organizativos da ecoformação que compõem novas formas de perceber toda a vida planetária e, ainda, compreendê-la como uma rede que só é vista como rede enquanto estão todos os pontos interligados. Portanto, o planeta é essa grande rede, e cada vida, ao ser atingida, deforma a rede e desestrutura todo o universo.

Nesse aspecto, Torre (2009, p. 24) entende "a ecoformação como uma maneira sintética, integradora e sustentável de entender a ação formativa, sempre em relação com o sujeito, a sociedade e a natureza". Para tanto, a ecoformação caminha em conjunto com a complexidade, uma vez que ela visa à integração dos saberes e também interliga os diferentes tipos de vida no universo. Em convergência com essa concepção, Silva (2008) afirma que a ecoformação se trata de uma formação que acontece durante toda a vida e em todos os contextos interligados com o ser humano, com o seu exterior e com o meio ambiente.

Nessa religação do todo da realidade humana, percebe-se a dimensão Projeção ecossistêmica e meio ambiente, que se trata de relação ecológica sustentável conforme 
apresentada por Torre et al. (2008). Essa dimensão é uma projeção que se interconecta com a visão do pensamento complexo, ao realizar a conexão entre o ser humano, o coletivo e o meio ambiente. Tal religação retrata a hologramática, que são ações humanas e ambientais nas quais uma intervém na outra, ou seja, a ação do homem repercute no ambiente, assim como as mudanças do meio ambiente atingem o humano e outros seres viventes.

Nessas relações, o ser humano pode optar por desfrutar dos recursos naturais de forma sustentável. Mas, se, ao contrário, impensadamente agir com abuso, sua desestruturação gerará também a desestruturação dos seres viventes, inclusive dele mesmo, uma vez que o "meio ambiente tem considerações científicas, socioculturais, políticas, econômicas, históricas, antropológicas, educativas e de saúde. Não é um simples campo do conhecimento, mas um espaço de encontro de múltiplos saberes intuitivos, científicos e tecnológicos" (Torre et al., 2008, p. 29).

Além dessas considerações com o meio ambiente, há também a beleza regeneradora ao transformar-se e reconstruir, minimamente, boa parte do que foi mutilado. Entretanto, muitas pessoas desconhecem as distintas agressões que têm atingido o potencial criador desse ambiente, tornando alguns males irrecuperáveis. Diante disso, Gadotti (2010, p. 77) afirma que "o meio ambiente forma tanto quanto ele é formado ou deformado. Precisamos de uma ecoformação para recuperarmos a consciência dessas experiências cotidianas".

O meio ambiente precisa ser percebido como parte que integra o ser humano e o planeta, pois, enquanto se tiver uma visão reducionista, fragmentada, o sujeito corre o risco de não conseguir compreender que sua ação, aparentemente isolada, interage com o universo. Assim, o meio ambiente é uma responsabilidade individual, social, política, organizacional e global.

Segundo Torre et al. (2008, p. 31), "nós não só vivemos na natureza, mas também vivemos dela e com ela. Nossa vida depende da qualidade dessa relação. E é por isso que a educação do meio ambiente precisa mais atenção do que recebe", uma vez que cuidar do meio ambiente não implica apenas a sua preservação no presente, mas também resultará positivo para gerações futuras. Por isso, fala-se da importância da formação integral do sujeito (ecoformação), por meio da epistemologia complexa, que propicia um olhar multidimensional e multirreferencial para a realidade planetária.

\section{Considerações finais}

Esta discussão intencionou articular diferentes visões que se integram ao contexto socioambiental e que resultam em reflexões para formações diferenciadas, para uma educação com fins diferentes de mera reprodução do conhecimento. Nesse sentido, uma proposta ecoformadora, ou seja, uma formação para a vida pode cooperar para a superação de situações adversas, contribuindo para transformá-las em potencialidades.

Apresentou-se como premissa a possibilidade reflexiva sobre o processo ecoformativo desenvolvido coletivamente em uma educação que visa um bem, atendendo o ser humano, a sociedade e o planeta de modo integral. Diante disso, por meio da epistemologia complexa, foi possível olhar a realidade de forma interligada, ou seja, compreender a formação vinculada ao meio socioambiental. 
Para compreender essas interligações, é importante trazer para a sociedade elementos diferenciados que compõem o processo formativo e que se fortalecem quando convergem com a concepção da epistemologia complexa. Portanto, é necessário ir além de um (re)pensar o processo de formação, para subsidiar um despertar socioambiental que possa inspirar educadores e seus entornos.

Esse despertar diz respeito a posturas e atitudes no exercício das profissões, no meio familiar e no convívio em sociedade conectado ao meio ambiente. Assim, pode-se perceber que há novas possibilidades para criar e inovar, pensar e construir um bem que seja tanto individual quanto social, tanto local quanto global, sendo da vida e para a vida.

\section{Referências}

André, M. E. D. A. (2013). O que é um estudo de caso qualitativo em educação. Educação e contemporaneidade. Revista da Faeeba, 22(4), jul./dez, 95-103)

Cunha, M. I. (2005). O professor universitário na transição de paradigmas. $2^{\mathrm{a}}$. ed. Araraquara: Junqueira \& Marin.

Dittrich, M. G., Espindola, S. S. e Koefender, M. (2013). Um olhar transdisciplinar e ecoformativo para a educação à saúde integral. In: M. V. R. Suanno, M. G. Dittrich e M. A. P. Maura (Org.). Resiliência, criatividade e inovação: potencialidades transdisciplinares na educação (pp. 163-173). Goiânia: UEG; América.

Gadotti, M. (2001). Pedagogia da terra: ecopedagogia e educação sustentável. In: Torres, C. A. (Org.). Paulo Freire y la agenda de la educación latinoamericana en el siglo XXI (pp. 81-132). Buenos Aires: CLACSO.

Gadotti, M. (2010). A carta da Terra na educação. São Paulo: Instituto Paulo Freire.

Galvani, P. e Pineau, G. (2012). Experiências de vida e formação docente: religando saberes - um método reflexivo e dialógico. In: M. C. Moraes e M. C. Almeida (Org.). Os sete saberes necessários à educação do presente: por uma educação transformadora (pp. 205-225). Rio de Janeiro: Wak.

Gil, A. C. (2002). Como elaborar projetos de pesquisa. 4a . ed. São Paulo: Atlas.

Humboldt, A. V. (1950). Quadros da natureza. Tradução: Assis Carvalho. Volume XXXIV. Rio de janeiro: W.W. Jackson.

Mallart, J. I. N. (2009). Ecoformação para a escola do século XXI. In: M. Zwierewicz e S. Torre (Coord.). Uma escola para o século XXI: escolas criativas e resiliência na educação (pp. 29-41). Florianópolis: Insular.

Marcolini, B. (2009). Humboldt, um visionário. Ciências hoje. Recuperado em 20 março de 2019, de http://www.cienciahoje.org.br/noticia/v/ler/id/1189/n/humboldt,_um_visionário.

Minayo, M. C. S. (Org.). (2001). Pesquisa social. Teoria, método e criatividade. $18^{\mathrm{a}}$ ed. Petrópolis: Vozes.

Moraes, M. C. (2008). Ecologia dos saberes: complexidade, transdisciplinaridade e educação: novos fundamentos para iluminar novas práticas educacionais. São Paulo: Antakarana/WHH - Willis Harman House. 
Moraes, M. C. (2014). Educação e sustentabilidade: um olhar complexo e transdisciplinar. In: M. C. Moraes e J. H. Suanno. (Org.). O pensar complexo na educação: sustentabilidade, transdisciplinaridade e criatividade (pp. 21-42). Rio de Janeiro: Wak.

Morin, E. (2000). Os sete saberes necessários à educação do futuro. Tradução de Catarina Eleonora F. da Silva e Jeanne Sawaya. 2a . ed. São Paulo: Cortez; Brasília: UNESCO.

Morin, E. (2001). Introdução ao pensamento complexo. $3^{\mathrm{a}}$. ed. Lisboa: Instituto Piaget.

Morin, E. (2009). Educação e complexidade: os sete saberes e outros ensaios. In: M. C. Almeida e E. A. Carvalho (Org.). Educação e complexidade: os sete saberes e outros ensaios. Tradução de Edgar de Assis Carvalho. 5a. ed. (pp. 1-104). São Paulo: Cortez.

Morin, E. (2015). Ensinar a viver: manifesto para mudar a educação. Tradução de Edgar de Assis Carvalho e Mariza Perassi Bosco. Porto Alegre: Sulina.

Neves, C. E. B. (2007). Desafios da educação superior. Sociologias, 9(17), jan./jun., 1421. Recuperado em 1 de abril de 2019, de http://www.scielo.br/pdf/soc/n17/a02n17.pdf.

Nicolescu, B. (1999). O manifesto da transdisciplinaridade. Tradução de Lucia Pereira de Souza. São Paulo: Triom.

Pinto, I. M. (2011). Docência inovadora na universidade. 2011. 365 f. Tese (Doutorado em Educação). Goiânia: Universidade Federal de Goiás.

Ribeiro, O. C. e Moraes, M. C. (2014). Criatividade em uma perspectiva transdisciplinar: rompendo crenças, mitos e concepções. Brasília: Liber Livro.

Santos, A. (2009). Complexidade e transdisciplinaridade em educação: cinco princípios para resgatar o elo perdido. In: A. Santos, A. Sommerman (Org.). Complexidade e transdisciplinaridade (pp. 15-38). Porto Alegre: Sulina.

Santos, A., Sanchez, S. B., Santos, A. C. S. e Bueno, E. S. S. (2014). Ensino integrado: justaposição ou articulação? In: A. Santos, A. e A. Sommerman (Org.). Ensino disciplinar e transdisciplinar: uma coexistência necessária (pp. 67-126). Rio de Janeiro: Wak.

Silva, A. T. R. (2008). Ecoformação: reflexões para uma pedagogia ambiental. In: Desenvolvimento e Meio Ambiente, 18, jan./jul, 95-104).

Torre, S. (2009). Um olhar ecossistêmico e transdisciplinar sobre a educação: olhar o futuro com outra consciência. In: M. Zwierewicz e Torre, S. (Coord.). Uma escola para o século XXI: escolas criativas e resiliência na educação (pp. 17-28). Florianópolis: Insular.

Torre, S. e outros (2008). Decálogo sobre transdisciplinaridade e ecoformação. In: S. Torre, M. A. Pujol, M. C. Moraes (Org.). Transdisciplinaridade e ecoformação: um novo olhar sobre a educação. Tradução de Suzana Vidigal (pp. 21-59). São Paulo: Triom.

Zwierewicz, M. (2011). Formação docente transdisciplinar na metodologia dos projetos criativos ecoformadores - PCE. In: S. Torre, M. Zwierewicz e E. C. Furlanetto, 
E. C. (Org.). Formação docente e pesquisa transdisciplinar - criar e inovar com outra consciência (pp. 141-158). Blumenau: Nova Letra.

Wulf, A. (2016). A invenção da natureza: a vida e as descobertas de Alexander von Humboldt/Andrea Wulf. Tradução de Renato Marques. São Paulo: Planeta.

' Essa onda se refere, de acordo com Torre (2009, p. 18), a "uma visão diferente da realidade oferecida pelas ciências que buscam uma teoria do todo". Nessa concepção, Morin (2001) percebe-a como a perspectiva do pensamento complexo para compreender a realidade.

ii Percebe-se que muitos autores citados se referem ao meio ambiente usando a palavra "natureza". Por se tratar de uma discussão que requer aprofundamento, pretende-se posteriormente avançar nesses estudos. Mas, nesta discussão, o uso dessa palavra refere-se aos recursos naturais e está relacionado ao conceito de meio ambiente.

iii De acordo com Gadotti (2001, p. 91), “a palavra ecologia foi criada em 1866 pelo biólogo alemão Ernst Haeckel (1834-1919), como um capítulo da biologia, para designar o estudo das relações existentes entre todos os sistemas vivos e não-vivos entre si e com seu meio ambiente".

Data de recepcão: $01 / 10 / 2019$

Data de revisão: $24 / 10 / 2019$

Data de aceite: $25 / 10 / 2019$ 